\title{
Evaluasi Performansi dan Strategi Perbaikan pada Lini Produksi Press Forming di PT Dirgantara Indonesia dengan Menggunakan Lean Assessment dan Lean Manufacturing
}

\author{
Imandio Wicaksono dan Putu Dana Karningsih \\ Departemen Teknik Industri, Fakultas Teknologi Industri, Institut Teknologi Sepuluh Nopember (ITS) \\ e-mail: putukarningsih@gmail.com
}

\begin{abstract}
Abstrak-PT Dirgantara Indonesia merupakan industri pesawat terbang yang telah mengimplementasikan konsep lean manufacturing sejak tahun 2013. Namun, masih terdapat permasalahan pada proses produksinya, diantaranya adalah tidak tercapainya target SQCDP (Safety, Quality, Cost, Delivery \& People) dan lead time produksi yang tinggi. Permasalahan tersebut menunjukkan bahwa implementasi lean manucaturing belum sesuai dengan rencana, sehingga perlu untuk dilakukan penilaian (lean assessment) dan perbaikan terhadap implementasi lean manufacturing tersebut. Dalam Tugas Akhir ini, lean assessment dilakukan dengan cara kuantitatif dan kualitatif. Dimensi yang diukur adalah efektivitas waktu, kualitas, proses, biaya, sumber daya manusia, pengiriman, pelanggan dan inventory. Setelah dilakukan pengukuran nilai leanness setiap dimensi digambarkan value stream mapping dan activity classification serta ditentukan dimensi dan waste kritis dengan borda count method. Kemudian dilakukan analisa penyebab waste kritis, analisa dampak permasalahan, penyusunan rekomendasi perbaikan, dan perhitungan nilai NPV untuk alternatif perbaikan terpilih. Berdasarkan hasil lean assessment, diketahui 3 dimensi kritis yaitu sumber daya manusia, pengiriman, dan efektivitas waktu. Value stream mapping yang diperoleh menunjukkan value added time sebesar 2.512 menit dari production lead time sebesar 18.844 menit. Output dari metode borda menunjukkan bahwa waiting, motion, dan transportation merupakan waste kritis. Untuk meminimasi pemborosan tersebut, perlu dilakukan penentuan jumlah mesin, operator, dan material handling yang optimal serta perhitungan jumlah sampling pada proses inspeksi.
\end{abstract}

Kata Kunci-Borda Count Method, Lean Assessment, Lean Manufacturing, Net Present Value, Root Cause Analysis, Stringer, Value Stream Mapping.

\section{PENDAHULUAN}

$\mathrm{P}_{\mathrm{n}}^{\mathrm{T}}$ Dirgantara Indonesia (PT DI) sedang dalam tahap melakukan pengembangan dan penyempurnaan proses pada fasilitas produksinya. Hal ini dilakukan karena terdapat permasalahan, yaitu PT DI belum sepenuhnya dapat memenuhi on time delivery terhadap produknya. Produk yang tidak dikirimkan kepada konsumen sesuai dengan jadwal yang telah direncanakan (on time delivery) menyebabkan adanya biaya pinalti yang dapat mengurangi profit bagi perusahaan. Salah satu usaha PT DI dalam melakukan pengembangan dan penyempurnaan proses pada fasilitas produksinya adalah menerapkan konsep lean. Lean manufacturing merupakan pendekatan untuk meningkatkan kualitas produk, meningkatkan produktivitas, mengurangi biaya, dan meningkatkan kepuasan pelanggan dengan mengeliminasi waste [21]. Meskipun konsep lean manufacturing pertama kali diterapkan dan berhasil pada industri otomotif, namun konsep lean manufacturing dapat juga dilakukan dan diterapkan dalam industri lainnya termasuk industri pesawat terbang [5]. Implementasi konsep lean manufacturing dilakukan di dalam Direktorat Produksi, yaitu pada bagian machining, sheet metal forming, dan surface treatment di divisi Detail Part Manufacturing. Implementasi tersebut seperti penggunaan tools 5R (Ringkas, Rapi, Resik, Rawat, dan Rajin), optimalisasi lay out, line balancing, total productive maintenance, kaizen dan meningkatkan nilai OEE (Overall Equipment Effectiveness) dari mesin produksi.

Berdasarkan hasil diskusi dengan pihak perusahaan, walaupun telah mengimplementasikan konsep lean manufacturing, masih terdapat beberapa permasalahan dalam lantai produksi yang mengakibatkan keterlambatan pengiriman produk. Masalah tersebut diantaranya adalah tingginya produk work in process (WIP) yang mengakibatkan bottleneck, waktu tunggu yang lama dari satu mesin ke mesin lain, idle pada proses produksi karena menunggu order dari SAP (System Analysis and Program Database), dan kemampuan pekerja yang tidak merata. Permasalahan ini tentunya memiliki dampak yang sangat besar terhadap lead time produksi. Pada Tabel 1 ditampilkan rincian proses produksi yang dilakukan pada bagian press forming.

Tabel 1.

Waktu Proses Produksi Bagian Press Forming

\begin{tabular}{cccccc}
\hline \hline & \multicolumn{1}{c}{$\begin{array}{c}\text { Standard } \\
\text { Preparatio } \\
\text { n Time } \\
\text { (Minutes) }\end{array}$} & $\begin{array}{c}\text { Standard } \\
\text { Process } \\
\text { Time } \\
\text { (Minutes) }\end{array}$ & $\begin{array}{c}\text { Actual } \\
\text { Preparatio } \\
\text { n Time } \\
\text { (Minutes) }\end{array}$ & $\begin{array}{c}\text { Actual } \\
\text { Process } \\
\text { Time } \\
(\text { Minute } \\
\text { s) }\end{array}$ \\
\hline 1 & $\begin{array}{l}\text { Router } \\
\begin{array}{l}\text { Fitter for } \\
\text { Router }\end{array}\end{array}$ & 6 & 46,2 & 38 & 120 \\
3 & $\begin{array}{l}\text { Rubber Press } \\
\text { Fitterfor } \\
\text { Rubber Press } \\
\text { Quality } \\
\text { Assessment }\end{array}$ & 3 & 17,4 & 5 & 210 \\
\hline \hline
\end{tabular}


Pada Tabel 1 diatas terlihat adanya gap antara waktu standar yang telah ditetapkan oleh perusahaan dengan waktu aktual yang terjadi selama proses produksi. Gap ini mengindikasikan adanya aktivitas selain value added yang terjadi selama proses produksi. Selain itu, dengan melihat data key performance indicator SQCDP (Safety, Quality, Cost, Delivery, People) lini produksi press forming pada periode bulan Januari tahun 2017 hingga bulan Februari tahun 2017 (Tabel 2), terdapat beberapa performance indicator yang tidak tercapai.

Tabel 2

SQCDP Lini Produksi Press Forming

\begin{tabular}{|c|c|c|c|c|c|c|c|c|c|c|}
\hline \multirow{2}{*}{$\begin{array}{c}\text { KPI } \\
\begin{array}{c}\text { Peri } \\
\text { od }\end{array}\end{array}$} & \multicolumn{2}{|c|}{$\begin{array}{c}\text { Safety } \\
\text { (Accident) }\end{array}$} & \multicolumn{2}{|c|}{$\begin{array}{c}\text { Quality } \\
\text { (Defect) }\end{array}$} & \multicolumn{2}{|c|}{$\begin{array}{c}\text { Cost } \\
(\text { Min/Produ } \\
c t) \\
\end{array}$} & \multicolumn{2}{|c|}{$\begin{array}{c}\text { Delivery } \\
\text { (Unit) }\end{array}$} & \multicolumn{2}{|c|}{$\begin{array}{c}\text { People } \\
(\% \text { Abbsenc } \\
e)\end{array}$} \\
\hline & $\begin{array}{l}\mathrm{Ja} \\
\mathrm{n}- \\
17\end{array}$ & $\begin{array}{c}\text { Feb- } \\
17\end{array}$ & $\begin{array}{l}\mathrm{Ja} \\
\mathrm{n}- \\
17\end{array}$ & $\begin{array}{l}\text { Feb } \\
-17\end{array}$ & $\begin{array}{l}\text { Jan } \\
-17\end{array}$ & $\begin{array}{c}\text { Feb- } \\
17\end{array}$ & $\begin{array}{l}\mathrm{Ja} \\
\mathrm{n}- \\
17\end{array}$ & $\begin{array}{l}\mathrm{Fe} \\
\mathrm{b}- \\
17\end{array}$ & $\begin{array}{l}\text { Jan } \\
-17\end{array}$ & $\begin{array}{c}\text { Feb- } \\
17\end{array}$ \\
\hline Real & 0 & 0 & 36 & 22 & $\begin{array}{c}66 \\
5\end{array}$ & $\begin{array}{c}60,1 \\
5\end{array}$ & $\begin{array}{l}48 \\
79\end{array}$ & $\begin{array}{l}50 \\
40\end{array}$ & $\begin{array}{l}98, \\
04\end{array}$ & $\begin{array}{c}92,1 \\
1\end{array}$ \\
\hline $\begin{array}{l}\text { Obje } \\
\text { ctive } \\
\text { Achi }\end{array}$ & 0 & 0 & 24 & 25 & $\begin{array}{l}59 \\
44\end{array}$ & $\begin{array}{c}59,4 \\
4\end{array}$ & $\begin{array}{l}69 \\
51\end{array}$ & $\begin{array}{l}62 \\
89\end{array}$ & $\begin{array}{c}95, \\
00\end{array}$ & $\begin{array}{c}95,0 \\
0\end{array}$ \\
\hline $\begin{array}{l}\text { eve } \\
\text { ment }\end{array}$ & $\checkmark$ & $\checkmark$ & $x$ & $\checkmark$ & $x$ & $\times$ & $x$ & $x$ & $\checkmark$ & $x$ \\
\hline
\end{tabular}

Berdasarkan deskripsi permasalahan dan analisa kondisi eksisting di atas, mengindikasikan bahwa perusahaan menyadari perlunya untuk melakukan pengukuran performansi dari implementasi lean (lean assessment) dan kebutuhan untuk melakukan perbaikan terhadap aplikasi lean manufacturing yang telah diterapkan di lini produksi press forming.

\section{METODE PENELITIAN}

\section{A. Tahap Identifikasi Awal}

Pada tahap identifikasi awal dilakukan studi lapangan untuk mengetahui kondisi permasalahan eksisting dan informasi mengenai objek amatan, studi pustaka untuk mendepatkan referensi terkait teori sebagai dasar penentuan rekomendasi alternatif perbaikan, perumusan masalah dan penentuan tujuan penelitian.

\section{B. Tahap Pengumpulan Data}

Pada tahapan ini dilakukan pengumpulan data-data yang diperlukan untuk mendukung penelitian yang ingin dilakukan. Data-data yang dikumpulkan antara lain adalah data produksi yang meliputi jumlah pesanan, SQCDP, waktu setup, lead time, delivery, defect, rework, scrap, dan kapasitas di lini produksi press forming.

\section{Tahap Define}

Pada tahap ini digambarkan value stream mapping (VSM) dari kondisi eksisting untuk mengetahui aliran informasi dan fisik (mateial) dan membuat activity classification dari objek penelitian.

\section{Tahap Measure}

Pada tahap ini dilakukan penentuan waste kritis yang terjadi pada objek penelitian dengan menggunakan metode borda count method (BCM) dengan rumus sebagai berikut. $b i=\sum_{k}(N-r i k)$

Parameter:

$b i=$ Nilai borda

$N=$ Jumlah kandidat alternatif

$r i k=$ Peringkat dari alternatif $\mathrm{i}$ berdasarkan kriteria $\mathrm{k}$

\section{E. Tahap Analyze}

Pada tahap ini dilakukan penentuan sumber penyebab terjadinya waste kritis dengan menggunakan root cause analysis (RCA) dan melakukan prioritas sumber penyebab waste kritis yang akan diberikan rekomendasi perbaikan dengan menggunakan pendekatan analisis risiko.

\section{F. Tahap Improve}

Pada tahap ini dilakukan penentuann alternatif rekomendasi perbaikan terhadap sumber penyebab waste kritis yang menjadi prioritas dan perhitungan nilai net present value (NPV) dari setiap alternatif perbaikan dengan rumus sebagai berikut.

$N P V=\sum_{t=0}^{n} F \mathrm{t}(1+\mathrm{i} *)-\mathrm{t}$

Parameter:

$N P V=$ Net present value

$F t=$ Aliran kas pada periode $\mathrm{t}$

$n=$ Horizon perencanaan (periode)

$i *=$ MARR

\section{HASIL DAN ANALISIS}

\section{A. Value Stream Mapping (VSM)}

Berikut merupakan VSM dari objek penelitian yang ditampilakan pada Gambar 1.

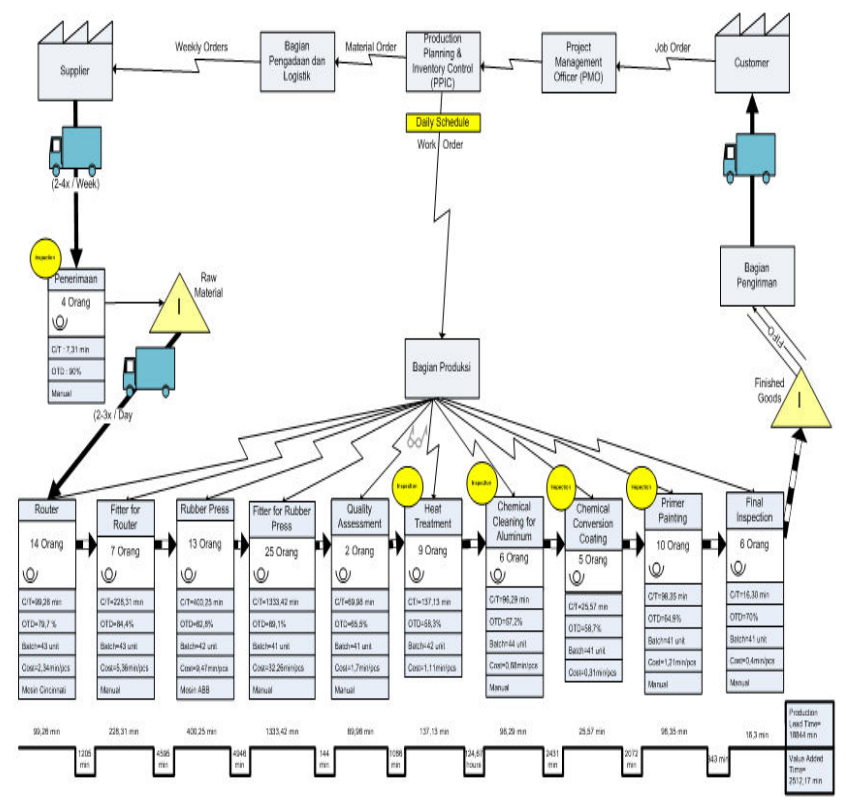

Gambar 1. Value Stream Mapping (VSM).

Berdasarkan value stream mapping kondisi eksisting perusahaan, dapat dilihat bahwa terdapat indikasi waste yang terjadi di beberapa proses produksi komponen stringer. Hal ini dapat dilihat dari tingginya production lead time yang mencapai 18.844 menit, sedangkan value added time hanya 
membutuhkan waktu 2512,17 menit atau hanya $13,33 \%$ dari keseluruhan waktu produksi.

Tabel 3. Rekapitulasi Jenis Aktivitas di Lini Produksi Press Forming

\begin{tabular}{clccc}
\hline \hline No & \multicolumn{1}{c}{ Proses } & VA & NNVA & NVA \\
\hline 1 & Router & 1 & 6 & 1 \\
2 & Fitter for Router & 3 & 3 & 2 \\
3 & Rubber Press & 1 & 8 & 2 \\
4 & Fitter for Rubber Press & 4 & 3 & 3 \\
5 & Quality Assessment & 0 & 6 & 2 \\
& Total & 9 & 26 & 10 \\
& Total \% & $20 \%$ & $58 \%$ & $22 \%$ \\
\hline \hline
\end{tabular}

Dengan melihat hasil activity classification terhadap kelima proses pada Tabel 3, mengindikasikan adanya waste yang terjadi selama proses produksi. Hal ini tentunya memberikan dampak terhadap lamanya waktu produksi pada setiap proses di lini produksi press forming. Oleh karena itu, perlu dilakukan analisis lebih lanjut terhadap penyebab permasalahan untuk mengetahui akar penyebab terjadinya waste tersebut.

\section{B. Identifikasi Waste Kritis dengan Borda Count Method (BCM)}

Penggunaan metode ini digunakan untuk mengetahui jenis waste kritis yang didapatkan dari penilaian masing-masing responden. Dari hasil kuesioner yang telah diberikan, diketahui urutan jenis waste kritis adalah waiting, motion, transportation, not utilizing employee's knowledge, skill and ability, inventory, excessive processing, defect, dan environmental, health, and safety (EHS).

\section{Root Cause Analysis (RCA)}

Pembangunan RCA dilakukan dengan menggunakan metode 5 whys terhadap permasalahan pada waste kritis. Dari hasil RCA yang telah dibangun, diketahui akar permasalahan dari setiap sub waste yang telah diidentifikasi.

Permasalahan pada waste waiting disebabkan oleh ketidakseimbangan antara workorder terhadap jumlah mesin, material handling, dan operator yang ada. Waste motion dikarenakan tidak adanya pencatatan waktu secara otomatis oleh mesin atau operator pada setiap operasi, tidak adanya operator khusus untuk membuat program pada proses router, tidak adanya operator khusus terhadap kebersihan tool pada proses rubber press, dan tidak adanya standar sampling dalam proses inspeksi. Waste transportation disebabkan oleh tidak adanya operator khusus untuk mengambil dan menaruh produk pada setiap operasi dan ketidakseimbangan antara jumlah workorder dengan material handling.

\section{Penentuan Prioritas Sumber Penyebab Waste Kritis dengan Pendekatan Analisis Risiko}

Pada penelitian tugas akhir ini, prioritas sumber penyebab waste kritis ditentukan oleh seberapa sering sumber penyebab waste terjadi (likelihood) dan dikalikan dengan dampak yang disebabkan (consequences). Dari hasil pemetaan akar penyebab waste kritis yang dilakukan, diketahui akar permasalahan yang diberikan alternatif rekomendasi perbaikan adalah ketidakseimbangan antara workorder terhadap jumlah mesin, material handling, dan operator yang ada, serta tidak adanya standar sampling dalam proses inspeksi.

\section{E. Penentuan Alternatif Rekomendasi Perbaikan}

Pada tahap ini akan dilakukan penentuan alternatif rekomendasi perbaikan terhadap prioritas sumber penyebab waste kritis. Rekomendasi perbaikan untuk menyelesaikan akar penyebab ketidakseimbangan antara jumlah workorder dengan jumlah mesin, operator, dan material handling dilakukan dengan menentukan jumlah mesin, operator, dan material handling yang optimal. Sehingga jumlah mesin, operator, dan material handling yang ada sesuai dengan permintaan / workorder yang telah ditentukan.

Pada hasil pehitungan jumlah mesin dan operator yang dilakukan, diketahui kebutuhan jumlah mesin dan operator pada setiap proses yang optimal, yaitu 3 unit mesin pada proses router, 7 orang operator pada proses fitter for routter, 5 unit mesin pada proses rubber press, 26 orang operator pada proses fitter for rubber press, dan 14 orang pada proses QA dengan penambahan jumlah shift menjadi 2 shift pada proses rubber press dan QA.

Pada alternatif perbaikan kedua dihasilkan kebutuhan penambahan jumlah material handling diantara proses fitter for router dan rubber press sebanyak 8 unit dan diantara proses fitter for rubber press dan QA sebanyak 15 unit dengan nilai availability dari material handling 0,7 .

Alternatif perbaikan berikutnya dilakukan penentuan jumlah sampling yang diambil dalam 1 batch. Dengan menggunakan konsep military standard 105E (ANS/ASQC ZI,4,ISO 2859) dihasilkan jumlah sampling yang diambil dalam 1 batch adalah sebanyak 8 unit dan menghasilkan penghematan waktu proses inspeksi sebesar 78,57\% dari 69,96 menit menjadi 14,99 menit.

\section{F. Perhitungan Net Present Value Rekomendasi Perbaikan}

Perhitungan NPV pada setiap rekomendasi perbaikan dilakukan untuk mengetahui kelayakan secara ekonomi dari setiap rekomendasi perbaikan. Dengan menghasilkan nilai NPV lebih dari nol $(>0)$ atau positif, menunjukkan bahwa rekomendasi tersebut secara ekonomi layak untuk dilakukan.

Pada hasil perhitungan NPV dari penentuan jumlah mesin dan operator yang optimal menghasilkan nilai NPV sebesar \$1.464.423 dan hasil perhitungan NPV dari perhitungan jumlah material handling menghasilkan NPV sebesar \$2.705 dalam periode waktu selama 10 tahun.

\section{KESIMPULAN/RINGKASAN}

Pada penelitian ini diketahui waste kritis yang terjadi di lini produksi press forming dengan menggunakan metode borda count method, yakni waiting, motion, dan transportation.

Akar permasalahan pada waste waiting disebabkan oleh ketidakseimbangan antara workorder terhadap jumlah mesin, material handling, dan operator yang ada. Waste motion dikarenakan tidak adanya pencatatan waktu secara otomatis oleh mesin atau operator pada setiap operasi, tidak adanya operator khusus untuk membuat program pada proses router, tidak adanya operator khusus terhadap kebersihan tool pada 
proses rubber press, dan tidak adanya standar sampling dalam proses inspeksi. Waste transportation disebabkan oleh tidak adanya operator khusus untuk mengambil dan menaruh produk pada setiap operasi dan ketidakseimbangan antara jumlah workorder dengan material handling.

Setelah dilakukan penentuan prioritas sumber penyebab waste kritis dengan pendekatan analisis risiko, diketahui prioritas sumber penyebab yang akan diberikan alternatif rekomendasi perbaikan. Rekomendasi perbaikan yang dipilih untuk dapat meminimalisir akar permasalahan dari waste kritis yang ditentukan dari hasil pendekatan analisa risiko diantaranya adalah penentuan jumlah mesin, operator, dan material handling yang sesuai dengan kondisi di lini produksi press forming serta perhitungan jumlah sampling dalam proses inspeksi yang dilakukan. Berdasarkan perhitungan nilai NPV yang dilakukan terhadap setiap alternatif perbaikan, diketahui kelayakan secara ekonomi dari setiap alternatif perbaikan untuk dilakukan. Pada alternatif perbaikan pertama dihasilkan nilai NPV sebesar \$1.464.423 dengan penambahan jumlah mesin router sebanyak 1 unit, mengurangi jumlah operator proses fitter for router sebanyak 2 orang, penambahan jumlah mesin rubber press sebanyak 3 unit dan perubahan jumlah shift kerja menjadi 2 shift, penambahan jumlah operator pada proses fitter for rubber press sebanyak 1 orang dan perubahan jumlah shift kerja menjadi 2 shift, dan penambahan operator pada proses QA sebanyak 12 orang. Pada alternatif perbaikan kedua dihasilkan nilai NPV sebesar $\$ 2.705$ dengan penambahan jumlah material handling diantara proses fitter for router dan rubber press sebanyak 8 unit dan diantara proses fitter for rubber press dan QA sebanyak 15 unit dengan nilai availability dari material handling 0,7. Alternatif perbaikan berikutnya dihasilkan jumlah sampling yang diambil dalam 1 batch sebnyak 8 unit menghasilkan penghematan waktu proses inspeksi sebesar 78,57\% dari 69,96 menit menjadi 14,99 menit.

\section{DAFTAR PUSTAKA}

[1] Almomani, M. A., Abdelhadi, A., Mumani, A., Momani, A. dan Aladeemy, M. (2014) "A proposed integrated model of lean assessment and analytical hierarchy process for a dynamic road map of lean implementation," International Journal of Advanced Manufacturing Technology, 72(1-4), hal. 161-172.

[2] Anityasari, M. dan Wessiani, N. A. (2011) Analisa Kelayakan Usaha. 1 ed. Surabaya: Guna Widya.

[3] Behrouzi, F. dan Wong, K. Y. (2011) "Lean performance evaluation of manufacturing systems: A dynamic and innovative approach," in Procedia Computer Science, hal. 388-395.

[4] Bhasin, S. (2008) "Lean and performance measurement," Journal of Manufacturing Technology Management, 19(5), hal. 670-684.

[5] Crute, V., Ward, Y., Brown, S. dan Graves, A. (2003) "Implementing Lean in aerospace - Challenging the assumptions and understanding the challenges," Technovation, 23(12), hal. 917-928.

[6] Dirgantara Indonesia, PT. (2017) Rencana Kerja \& Anggaran Produksi (RKAP).
[7] Doggett, A. M. (2005) "Root cause analysis: a framework for tool selection," The Quality Management Journal, 12(4), hal. 34-45.

[8] Doolen, T. L. dan Hacker, M. E. (2005) "A review of lean assessment in organizations: An exploratory study of lean practices by electronics manufacturers," Journal of Manufacturing Systems, hal. 55-67.

[9] Emerson, P. (2013) "The original Borda count and partial voting," Social Choice and Welfare, 40(2), hal. 353-358.

[10] Feld, W. M., (2001). Lean Manufacturing : Tools, Techniques, and How To Use Them. Florida: The St. Lucie Press/APICS Series on Resource Management.

[11] Fraenkel, J. dan Grofman, B. (2014) "The Borda Count and its realworld alternatives : Comparing scoring rules in Nauru and Slovenia," Australian Journal of Political Science, 49(2), hal. 186-205.

[12] Gaspersz, V. (2006). Continuous Cost Reduction Through Lean-Sigma Approach. Jakarta: Gramedia Pustaka Utama.

[13] George, M. O., (2010). The Lean Six Sigma Guide to Doing More with Less : Cut Costs, Reduce Waste, and Lower Your Overhead, New Jersey: John Wiley \& Sons, Inc.

[14] Groover, M. P., (2007). Automation Production Systems and Computer Integrated Manufacturing, New Jersey: Prentice Hall Press.

[15] Hamad, W. A., Crowe, J. dan Arisha, A. (2012) "Towards leaner healthcare facility: Application of simulation modelling and value stream mapping," 1st International Workshop on Innovative Simulation for Health Care, IWISH 2012, Held at the International Multidisciplinary Modeling and Simulation Multiconference, I3M 2012, September 19, 2012 - September 21, 2012, 19, hal. 149-155.

[16] Hines, P., Rich, N., Bicheno, J., Brunt, D., Taylor, D., Butterworth, C. dan Sullivan, J. (1998) "Value Stream Management," The International Journal of Logistics Management, 9(1), hal. 25-42.

[17] Jing, G. (2008) "Digging For The Root Cause," Six Sigma Forum Magazine, hal. 19-24.

[18] Karlsson, C. dan Ahlstrom, P. (1996) "Assessing changes towards lean production," International Journal of Operations \& Production Management, 16(2), hal. 24.

[19] Knoema. (2017). Indonesia Inflation Forecasat 2016-2026 and up to 2060.

[20] Lansdowne, Z. F. \& Woodward, B. S., (1996). Applying Borda Ranking Method. Air Force Jornal of Logistics, hal. 27-29.

[21] Manos, A. dan Vincent, C. (2012) The Lean Certification Handbook: A Guide To The Bronze Certification Body of Knowledge. Milwaukee, Wisconsin: ASQ Quality Press.

[22] Mann, D. (2014) Creating a Lean Culture - Tools to Sustain Lean Conversions, 2014.

[23] Monden, Y., (1983). The Toyota Production System. s.l.:Productivity Press.

[24] Montgomery, D. C., (2009). Introduction to Statistical Quality Control Sixth Edition, New Jersey: John Wiley \& Sons, Inc.

[25] Ohno, T. (1988) Toyota Production System, International Journal of Operations.

[26] Pakdil, F. dan Leonard, K. M. (2014) "Criteria for a lean organisation: development of a lean assessment tool," International Journal of Production Research, 52(15), hal. 4587-4607.

[27] Pujawan, I. N., (2004). Ekonomi Teknik. 1st ed. Surabaya: Guna Widya.

[28] Saary, M. J. (2008) "Radar plots: a useful way for presenting multivariate health care data," Journal of Clinical Epidemiology, 61(4), hal. 311-317.

[29] Shingo, S., (1988). Non-Stock Production : The Shingo System for Continuous Improvement. Cambridge: Productivity Press.

[30] Suciu, E. S. dan Apreutesei, M. (2011) "Value stream mapping - a lean production methodology," 11(1), hal. 184-196.

[31] Womack, J. P., \& Jones, D. T. (1996) "Lean Thinking by Womack and Jones," Review Literature And Arts Of The Americas, (November), hal. 5. 